\title{
Nickel nanoparticles: A highly efficient catalyst for one pot synthesis of tetraketones and biscoumarins
}

\author{
JITENDER M KHURANA* and KANIKA VIJ \\ Department of Chemistry, University of Delhi, Delhi 110 007, India \\ e-mail: jmkhurana1@yahoo.co.in
}

MS received 18 March 2011; revised 17 November 2011; accepted 20 December 2011

\begin{abstract}
A novel and practically useful protocol has been designed wherein, polyvinyl pyrrolidone (PVP) stabilized nickel nanoparticles have been used as a catalyst for promoting the synthesis of $2,2^{\prime}$-aryl-methylene bis(3-hydroxy-5,5-dimethyl-2-cyclohexene-1-one), 2,2'-aryl-methylene bis(3-hydroxy-2-cyclohexene-1-one), also known as tetraketones, and biscoumarins via Knoevenagel condensation followed by rapid Michael addition.
\end{abstract}

Keywords. PVP-stabilized Ni nanoparticles; ethylene glycol; tetraketones; biscoumarins; cyclo-condensation.

\section{Introduction}

Tetraketones such as 2,2'-aryl-methylene bis(3hydroxy-5,5-dimethyl-2-cyclohexene-1-one) or tetraketones (3), are important precursors extensively used in the synthesis of acridinediones, as laser dyes and for the synthesis of various heterocyclic compounds. ${ }^{1}$ Tetraketones show significant lipoxygenase inhibitor activity and strong anti-oxidant potential. ${ }^{2}$ They exhibit broad spectrum of therapeutic and biological properties. ${ }^{3-5}$ 3,3'-(4-aryl methylene) bis-(4hydroxycoumarin), commonly known as biscoumarins (4), are of considerable interest due to their biological activities, e.g., anticoagulant activity, ${ }^{6}$ prevention and treatment of thrombosis, ${ }^{7}$ urease inhibitors. ${ }^{8}$ Various methods have been reported for the synthesis of compounds belonging to these classes: (3 and 4). ${ }^{9-18}$ Each of these methods have their own advantages but also suffer from certain disadvantages such as prolonged reaction time, tedious work-up processes, low yield, high temperature and hazardous reaction conditions.

Transition metal nanoparticles have gained tremendous importance due to their interesting electrical, optical, magnetic, chemical properties, and especially catalytic properties, which cannot be achieved by their bulk counterparts. ${ }^{19-21}$ Recently, there has been growing interest in using nickel nanoparticles in organic synthesis owing to their easy preparation, potent catalytic activity, possible processability, high stability and ease of recyclability compared to traditional

*For correspondence
Raney Ni catalyst. Ni nanoparticles have been used as catalyst for functional group transformations like transfer hydrogenation of carbonyl compounds, ${ }^{22-24}$ reductive amination of aldehydes, ${ }^{25}$ alkylation of ketones and indirect $a z a$-Wittig reaction with alcohols, ${ }^{26}$ oxidative coupling of thiols ${ }^{27}$ and Hantzsch condensation for polyhydroquinoline derivatives. ${ }^{28}$ Recently, we have reported the Knoevenagel condensation of aldehydes with barbituric acids ${ }^{29}$ and with $o$-phenylene diamine and 2-aminothiophenol ${ }^{30}$ catalyzed efficiently by PVP-stabilized $\mathrm{Ni}(0)$ nanoparticles in ethylene glycol prepared by the polyol method. ${ }^{31}$ We have also reported nickel nanoparticles catalyzed chemoselective Knoevenagel condensation of Meldrum's acid and tandem enol lactonizations via cascade cyclization sequence. ${ }^{32}$ One of the prime steps in the synthesis of tetraketones and biscoumarins is the Knoevenagel condensation of aldehydes with dimedone. Therefore, we envisaged the possibility of applying nickel nanoparticles for the synthesis of $\mathbf{3}$ and $\mathbf{4}$.

\section{Experimental}

\subsection{General}

All the chemicals used were of research grade and were used without further purification. The size and morphology of nickel nanoparticles were characterized with the help of TEM (JEOL 2100-F operating at $200 \mathrm{kV}$ ) and QELS analysis (PHOTOCOR-FC-1135P). ${ }^{1}$ HNMR spectra were recorded on Brucker Spectrospin AVANCE (300 MHz). IR spectra were recorded on 
Perkin-Elmer FT-IR SPECTRUM-2000. X-ray diffraction pattern was obtained on BRUKER D8.

\subsection{Preparation of Ni nanoparticles}

Nickel nanoparticles were prepared by the modified polyol process. ${ }^{31} 2 \times 10^{-4} \mathrm{molL}^{-1}$ solution of $\mathrm{NiCl}_{2} \cdot 6 \mathrm{H}_{2} \mathrm{O}$ in ethylene glycol was reduced with $\mathrm{NaBH}_{4}$ in the presence of PVP $\left(\mathrm{Ni}^{2+}\right.$ : PVP:: 1: $\left.5 \mathrm{wt} \%\right)$ at $140^{\circ} \mathrm{C}$. The sample for TEM was prepared by addition of acetone to the nickel nanoparticles dispersion in ethylene glycol, followed by centrifugation $(6000 \mathrm{rpm})$. The particles, so obtained, were washed free of any residual components using ethanol. Methanol dispersion of the nickel nanoparticles was placed on carbon coated $\mathrm{Cu}$ grid (mesh size 300). The ethylene glycol dispersion was used as such for QELS analysis. Sample for the X-ray diffraction was obtained by depositing a thin-coating of the isolated nickel nanoparticles (dispersed in absolute ethanol) onto a glass plate followed by vacuum drying.

\subsection{General procedure for the synthesis of} 2,2'-aryl-methylene bis(3-hydroxy-5,5-dimethyl-2cyclohexene-1-one) and 2,2'-aryl-methylene bis(3-hydroxy-2-cyclohexene-1-one) (3a-z)

In a typical experiment, 4-bromobenzaldehyde ( $2 \mathrm{mmol}$ ) was added to a well stirred dispersion of nickel nanoparticles in ethylene glycol $(2 \mathrm{~mL} / 0.1 \mathrm{~g}$ of 1) in a $25 \mathrm{~mL}$ reaction flask. Dimedone $(2,4 \mathrm{mmol})$ was added to the mixture and the stirring was continued. The progress of the reaction was monitored by TLC using petroleum ether: ethyl acetate (70:30, v/v) as eluent. After completion of the reaction, the solid product was filtered using a pump, washed with water, dried and recrystallised from hot ethanol. 2, 2'-(4bromophenyl)-methylene bis(3-hydroxy-5, 5-dimethyl2-cyclohexene-1-one) (3a, 93\%) was obtained as identified by m.p. $155^{\circ} \mathrm{C}$ (lit $158-159^{\circ} \mathrm{C}$ ) and spectral data.

3a: M.P. $=155^{\circ} \mathrm{C}\left(\right.$ lit. $\left.^{9} 158-159^{\circ} \mathrm{C}\right)$; IR $\left(\mathrm{KBr}, \mathrm{cm}^{-1}\right)$ $v_{\max }=3053,2959,2873,1723,1594 .{ }^{1} \mathrm{H} \mathrm{NMR}$ $\left(300 \mathrm{MHz}, \mathrm{CDCl}_{3}\right) \delta: 1.13(\mathrm{~s}, 6 \mathrm{H}, 2 \mathrm{Me}), 1.23(\mathrm{~s}, 6 \mathrm{H}$, 2Me), 2.20-2.53 (m, 8H, 4CH $), 5.47(\mathrm{~s}, 1 \mathrm{H}, \mathrm{CH}), 6.96$ $(\mathrm{d}, 2 \mathrm{H}, \mathrm{J}=6.6 \mathrm{~Hz}, \mathrm{H}-\mathrm{Ar}), 7.38(\mathrm{~d}, 2 \mathrm{H}, \mathrm{J}=6.6 \mathrm{~Hz})$, 11.93 (brs, 1H, OH).

\subsection{General procedure for the synthesis of 3,3'- (4-aryl methylene) bis-(4-hydroxycoumarins) (4a-f)}

In a typical experiment, 4-chlorobenzaldehyde ( $2 \mathrm{mmol}$ ) was added to a well-stirred dispersion of nickel nanoparticles in ethylene glycol $(2 \mathrm{~mL} / 0.1 \mathrm{~g}$ of $\mathbf{1}$ ) in a $25 \mathrm{~mL}$ reaction flask. 4-Hydroxycoumarin (4 mmol) was added to the mixture and the stirring was continued. The progress of the reaction was monitored by TLC using petroleum ether: ethyl acetate $(60: 40$, $\mathrm{v} / \mathrm{v})$ as eluent. After completion of the reaction, the solid product was filtered using a pump, washed with water, dried and recrystallized from hot ethanol. 3, 3'(4-chlorophenylmethylene)-bis-(4-hydroxycoumarin)

$(\mathbf{4 a}, 92 \%)$ was obtained as identified by m.p. $250^{\circ} \mathrm{C}$ (lit. $252-254^{\circ} \mathrm{C}$ ) and spectral data.

4a: M.P. $=250^{\circ} \mathrm{C}\left(\right.$ lit. $\left.^{17} 252-254^{\circ} \mathrm{C}\right)$; $\operatorname{IR}\left(\mathrm{KBr} \mathrm{cm}^{-1}\right)$ : $v_{\max }=3075,2919,2733,1663,1612,1567 .{ }^{1} \mathrm{HNMR}$ $\left(300 \mathrm{MHz}, \mathrm{CDCl}_{3}\right) \delta: 6.03(\mathrm{~s}, 1 \mathrm{H}, \mathrm{CH}), 7.13-7.29(\mathrm{~m}$, 4H, H-Ar), 7.35-7.42 (m, 4H, H-Ar), 7.60-7.66 (m, 2H, $\mathrm{H}-\mathrm{Ar}$ ), 7.97-8.07 (m, 2H, H-Ar), 11.31 (s, 1H, OH), $11.53(\mathrm{~s}, 1 \mathrm{H}, \mathrm{OH})$.

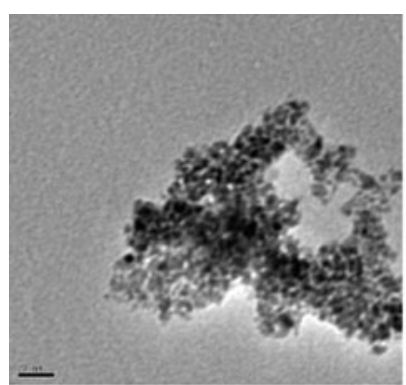

(a)

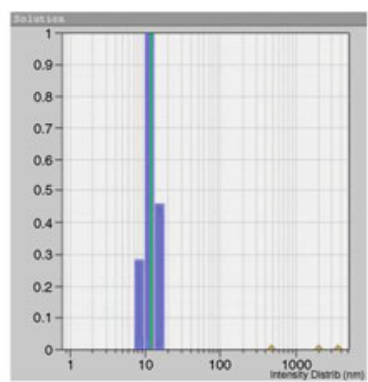

(b)

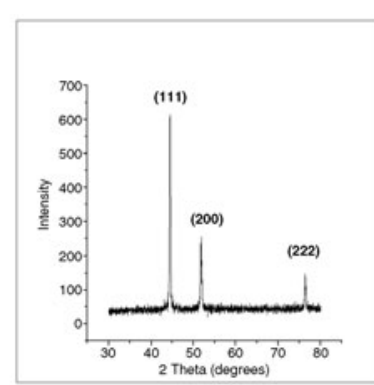

(c)

Figure 1. (a) HRTEM image of Ni nanoparticles. The scale bar corresponds to $20 \mathrm{~nm}$ in the images; (b) QELS data of Ni nanoparticles: plot of population distribution in percentile versus size distribution in nanometers $(\mathrm{nm})$; (c) X-ray diffraction pattern of PVP-Ni nanoparticles. 


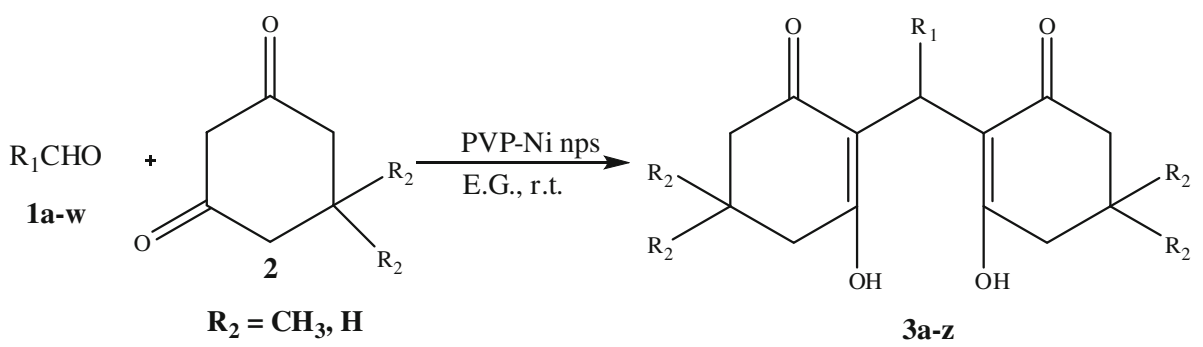

Scheme 1. PVP-Ni nanoparticles catalyzed synthesis of tetraketones (3a-z).

\subsection{General procedure for the recyclability of the catalyst}

Aldehyde (1a, 2 mmol) was added to nickel nanoparticle dispersion in ethylene glycol $(2 \mathrm{~mL} / 0.1 \mathrm{~g} \mathrm{1})$ in $25 \mathrm{~mL}$ reaction flask. Dimedone $(\mathbf{2}, 4 \mathrm{mmol})$ was added to the reaction mixture and it was stirred. Upon complete formation of $\mathbf{3 a}$ as monitored by TLC, $10.0 \mathrm{~mL}$ of ethyl acetate was added to the reaction mixture. The reaction mixture was stirred until complete dissolution of 3a in ethyl acetate was observed. The two layers were then separated. The ethylene glycol layer was sonicated for 5-10 min and reused for the same experiment for over five cycles.

\section{Results and discussion}

We report here a simple and highly efficient route for the synthesis of 2,2'-aryl-methylene bis(3-hydroxy-5,5-

Table 1. PVP stabilized Ni nanoparticles catalysed synthesis of 2,2'-aryl-methylene bis(3-hydroxy-5,5dimethyl-2-cyclohexene-1-one) and 2,2'-aryl-methylene bis(3-hydroxy-2-cyclohexene-1-one) (3a-z).

\begin{tabular}{|c|c|c|c|c|c|c|c|}
\hline \multirow[b]{2}{*}{ Entry } & \multirow[b]{2}{*}{$\mathrm{R}_{1}$} & \multirow[b]{2}{*}{$\mathrm{R}_{2}$} & \multirow[b]{2}{*}{ Product } & \multirow[b]{2}{*}{ Time (min.) } & \multirow[b]{2}{*}{ Yield (\%) } & \multicolumn{2}{|c|}{ M.P. $\left({ }^{\circ} \mathrm{C}\right)$} \\
\hline & & & & & & Obs. & Lit. \\
\hline 1. & $4-\mathrm{BrC}_{6} \mathrm{H}_{4}(\mathbf{1 a})$ & $\mathrm{CH}_{3}$ & 3a & 10 & 93 & 155 & $158-159^{11}$ \\
\hline 2. & $4-\mathrm{MeOC}_{6} \mathrm{H}_{4}(\mathbf{1 b})$ & $\mathrm{CH}_{3}$ & $3 b$ & 10 & 90 & 138 & $142-143^{9}$ \\
\hline 3. & $3,4,5-(\mathrm{MeO})_{3} \mathrm{C}_{6} \mathrm{H}_{2}(\mathbf{1 c})$ & $\mathrm{CH}_{3}$ & $3 c$ & 10 & 96 & 186 & $189-191^{15}$ \\
\hline 4. & $\mathrm{C}_{6} \mathrm{H}_{5}(\mathbf{1 d})$ & $\mathrm{CH}_{3}$ & 3d & 10 & 88 & 204 & $194-195^{9}$ \\
\hline 5. & $4-\mathrm{O}_{2} \mathrm{NC}_{6} \mathrm{H}_{4}(\mathbf{1 e})$ & $\mathrm{CH}_{3}$ & $3 e$ & 10 & 91 & 190 & $188-190^{9}$ \\
\hline 6. & $4-\mathrm{MeC}_{6} \mathrm{H}_{4}(\mathbf{1 f})$ & $\mathrm{CH}_{3}$ & 3f & 15 & 86 & 132 & $126-128^{2}$ \\
\hline 7. & $4-\mathrm{ClC}_{6} \mathrm{H}_{4}(\mathbf{1 g})$ & $\mathrm{CH}_{3}$ & $3 g$ & 10 & 92 & 144 & $141-143^{11}$ \\
\hline 8. & $2-\mathrm{BrC}_{6} \mathrm{H}_{4}(\mathbf{l h})$ & $\mathrm{CH}_{3}$ & $3 \mathbf{h}$ & 10 & 92 & 187 & $194-195^{10}$ \\
\hline 9. & $3-\mathrm{O}_{2} \mathrm{NC}_{6} \mathrm{H}_{4}(\mathbf{1 i})$ & $\mathrm{CH}_{3}$ & $3 \mathbf{i}$ & 10 & 90 & 190 & $197-198^{9}$ \\
\hline 10. & $2,4-\mathrm{Cl}_{2} \mathrm{C}_{6} \mathrm{H}_{3}(\mathbf{1} \mathbf{j})$ & $\mathrm{CH}_{3}$ & $3 \mathbf{j}$ & 10 & 89 & 200 & $203-204^{11}$ \\
\hline 11. & $4-\mathrm{Me}_{2} \mathrm{NC}_{6} \mathrm{H}_{4}(\mathbf{1 k})$ & $\mathrm{CH}_{3}$ & $3 \mathbf{k}$ & 10 & 90 & 193 & $195-196^{9}$ \\
\hline 12. & $4-\mathrm{HOC}_{6} \mathrm{H}_{4}(\mathbf{1 l})$ & $\mathrm{CH}_{3}$ & 31 & 10 & 87 & 180 & $187-189^{9}$ \\
\hline 13. & $4-\mathrm{FC}_{6} \mathrm{H}_{4}(\mathbf{1 m})$ & $\mathrm{CH}_{3}$ & $3 m$ & 10 & 93 & 165 & $167-168^{14}$ \\
\hline 14. & $\mathrm{CH}_{3} \mathrm{CH}_{2} \mathrm{CH}_{2}(\mathbf{1 n})$ & $\mathrm{CH}_{3}$ & $3 n$ & 10 & 88 & 130 & $134-135^{9}$ \\
\hline 15. & $\mathrm{C}_{6} \mathrm{H}_{5} \mathrm{CH}=\mathrm{CH}(\mathbf{1 0})$ & $\mathrm{CH}_{3}$ & 30 & 15 & 89 & 204 & $215-217^{9}$ \\
\hline 16. & 1-Naphthyl (1p) & $\mathrm{CH}_{3}$ & $3 \mathbf{p}$ & 10 & 91 & 190 & $195^{12}$ \\
\hline 17. & 2-Pyridinyl (1q) & $\mathrm{CH}_{3}$ & $3 q$ & 15 & 89 & 172 & $175-177^{10}$ \\
\hline 18. & $2-\mathrm{HOC}_{6} \mathrm{H}_{4}(\mathbf{1 r})$ & $\mathrm{CH}_{3}$ & $3 r$ & 10 & 94 & 202 & $205-206^{9}$ \\
\hline 19. & 2-Furanyl (1s) & $\mathrm{CH}_{3}$ & $3 s$ & 8 & 89 & 146 & $152-153^{2}$ \\
\hline 20. & $\mathrm{CH}_{3} \mathrm{CH}=\mathrm{CH}(\mathbf{1 t})$ & $\mathrm{CH}_{3}$ & $3 t$ & 10 & 88 & 186 & $193-194^{9}$ \\
\hline 21. & $\left(\mathrm{CH}_{3}\right)_{2} \mathrm{CH}(\mathbf{1 u})$ & $\mathrm{CH}_{3}$ & $3 \mathbf{u}$ & 10 & 88 & 152 & $153-154^{9}$ \\
\hline 22. & $\mathrm{n}-\mathrm{C}_{6} \mathrm{H}_{13}(\mathbf{1 v})$ & $\mathrm{CH}_{3}$ & $3 v$ & 12 & 86 & 100 & $101-103^{9}$ \\
\hline 23. & $2-\mathrm{HO}-3-\mathrm{MeO}-\mathrm{C}_{6} \mathrm{H}_{3}(\mathbf{1 w})$ & $\mathrm{CH}_{3}$ & $3 \mathbf{w}$ & 10 & 87 & 225 & $229-231^{16}$ \\
\hline 24. & $4-\mathrm{ClC}_{6} \mathrm{H}_{4}(\mathbf{1 g})$ & $\mathrm{H}$ & $3 \mathbf{x}$ & 8 & 90 & 200 & $202-203^{13}$ \\
\hline 25. & $4-\mathrm{BrC}_{6} \mathrm{H}_{4}(\mathbf{1 a})$ & $\mathrm{H}$ & $3 \mathbf{y}$ & 10 & 92 & 236 & $240-241^{13}$ \\
\hline 26. & $4-\mathrm{O}_{2} \mathrm{NC}_{6} \mathrm{H}_{4}(\mathbf{1 e})$ & $\mathrm{H}$ & $3 z$ & 7 & 89 & 190 & $194-196^{13}$ \\
\hline
\end{tabular}




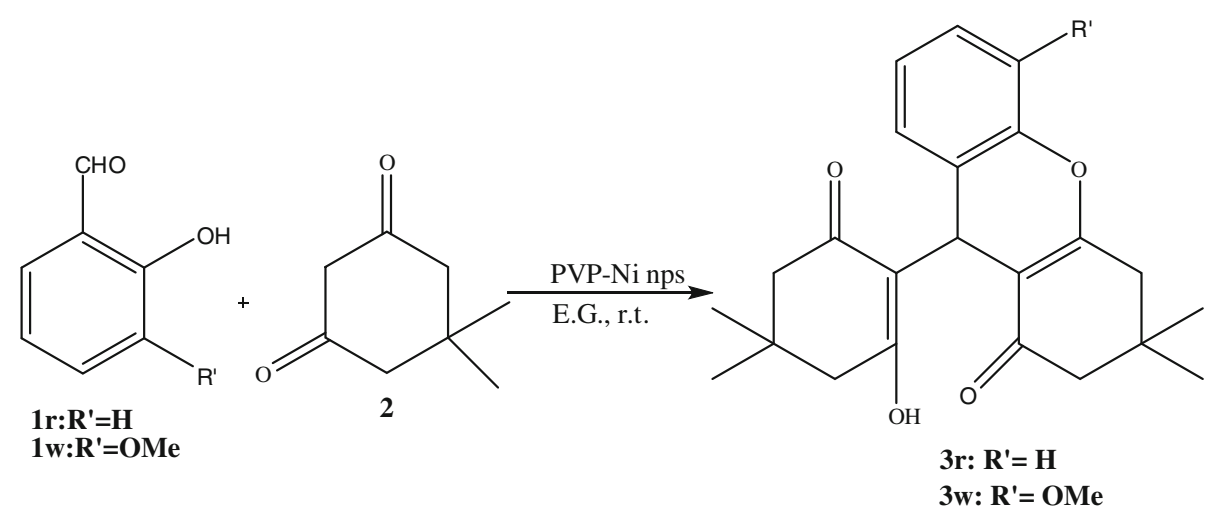

Scheme 2. PVP-Ni nanoparticles catalyzed reaction of ortho-hydroxy benzaldehydes and dimedone.

dimethyl-2-cyclohexene-1-one) and 2,2'-aryl-methylene bis(3-hydroxy-2-cyclohexene-1-one) (3) starting from aldehydes and dimedone, and also the synthesis of biscoumarins (4) from aldehydes and 4hydroxycoumarin, using highly monodispersed nickel nanoparticles as catalyst in ethylene glycol. The nickel nanoparticles were obtained as air-stable nanoparticulate monodispersion by modified polyol method ${ }^{31}$ in ethylene glycol from nickel chloride hexahydrate and sodium borohydride using polyvinylpyrrolidone (PVP) as the stabilizing agent (equation 1).

$$
\begin{aligned}
& 2 \mathrm{Ni}^{2+}(\mathrm{eg})+\mathrm{BH}_{4}^{-}(\mathrm{s})+2 \mathrm{H}_{2} \mathrm{O}(\mathrm{eg})+2 \mathrm{nPVP}(\mathrm{eg}) \\
\rightarrow & 2 \mathrm{Ni}(\mathrm{PVP})_{\mathrm{n}}(\mathrm{s})+2 \mathrm{H}_{2}(\mathrm{~g})+4 \mathrm{H}^{+}(\mathrm{eg})+\mathrm{BO}_{2}^{-}(\mathrm{eg}) .
\end{aligned}
$$

The metal dispersion so obtained was characterized by TEM analysis which revealed the formation of coated Ni nanoparticles with average diameter $11 \mathrm{~nm}$ (figure 1a) which was further supported by QELS analysis that showed a maximum population distribution centred around $11 \mathrm{~nm}$ (figure 1b). XRD analysis further supported the results (figure 1c).

The versatility of the catalyst was investigated for the condensation of dimedone with aldehydes. The

Table 2. Reactions to confirm involvement of Ni nanoparticles during synthesis of $\mathbf{3}$.

\begin{tabular}{lccc}
\hline S. No. & Reaction condition & Time & Yield (3a, \%) \\
\hline 1. & Ethylene glycol alone & $6 \mathrm{~h}^{\mathrm{a}}$ & 40 \\
2. & Ni powder (size $<150$ micron) & $--^{\mathrm{a}}$ & 45 \\
3. & $\mathrm{NiCl}_{2} \cdot 6 \mathrm{H}_{2} \mathrm{O}$ alone in EG & $8 \mathrm{~h}^{\mathrm{a}}$ & 42 \\
4. & $\mathrm{NaBH}_{4}$ alone in EG & $5 \mathrm{~h}^{\mathrm{b}}$ & - \\
5. & Isolated Ni nanoparticles & $15 \mathrm{~min}$ & 90 \\
& redispersed in EG & & \\
\hline
\end{tabular}

${ }^{\mathrm{a}}$ incomplete reaction; ${ }^{\mathrm{b}}$ mixture of products reactions of 4-bromobenzaldehyde (1a) and dimedone with varying amounts of nickel nanoparticulate dispersion in ethylene glycol were monitored by TLC. The reaction was complete using 1:2 molar ratio of aldehyde to dimedone in $10 \mathrm{~min}$ and $93 \%$ of $2,2^{\prime}-(4-$ bromophenyl)-methylene bis(3-hydroxy-5, 5-dimethyl2-cyclohexene-1-one) (3a) was obtained as identified by $\mathrm{mp}$ and spectral data. The reaction of $\mathbf{1 a}$ and dimedone in equimolar ratio gave a mixture of $\mathbf{3} \mathbf{a}$ and unreacted aldehyde. Subsequent reactions of dimedone with several aldehydes containing electron-donating as well as electron-withdrawing groups underwent smooth and effective one-pot Knoevenagel condensation followed by Michael addition in the presence of PVP-coated $\mathrm{Ni}$ nanoparticles to give tetraketones $(\mathbf{3 b}-\mathbf{w})$. The aldehydes also underwent efficient Knoevenagel condensation and Michael addition with cyclohexane-1,3-dione to give the corresponding 2,2'-aryl-methylene bis(3hydroxy-2-cyclohexene-1-one) (3x-z) (scheme 1, table $1)$. The condensation could be achieved with aryl, alkyl, $\alpha, \beta$-unsaturated (10 and 1t) as well as heteroaryl aldehydes (1q and $\mathbf{1 s})$. The products (3r and $\mathbf{3 w}$ )

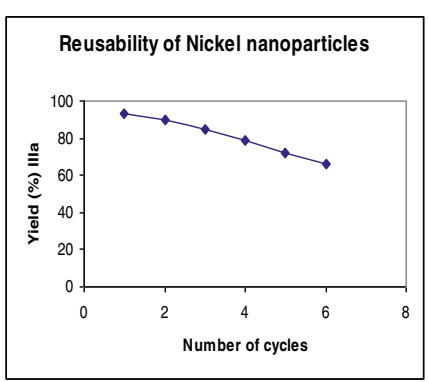

(a)

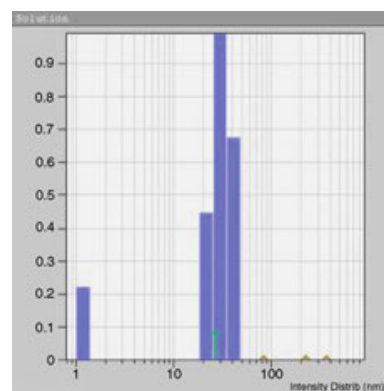

(b)
Figure 2. (a) Recyclability data of PVP-Ni nanoparticles; (b) QELS data of recycled Ni nanoparticles after 4th cycle: Plot of population distribution in percentile versus size distribution in nanometers (nm). 


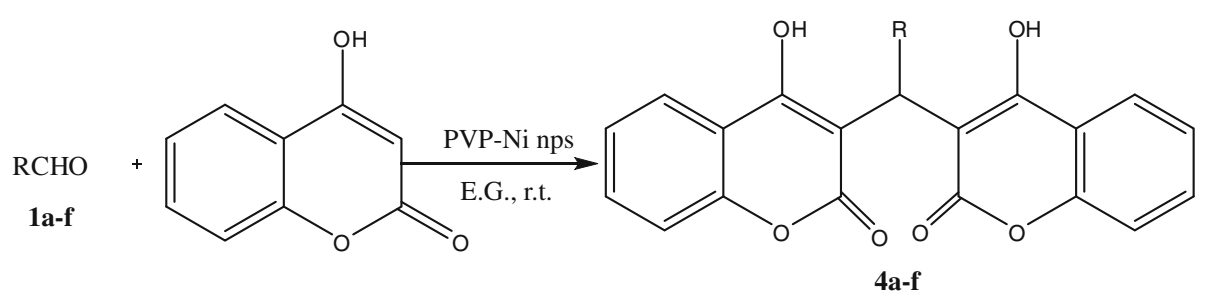

Scheme 3. PVP-Ni nanoparticles catalyzed synthesis of biscoumarins (4a-f).

obtained from the reaction of salicylaldehyde (1r) and 2-hydroxy-3-methoxy benzaldehyde (1w) with dimedone has been assigned a pyran structure (scheme 2).

The role of nickel nanoparticles in catalyzing the formation of tetraketones (3a-z) was confirmed by a blank reaction of 1a with dimedone in ethylene glycol in the absence of catalyst. The reaction was incomplete even after $6 \mathrm{~h}$ of stirring though formation of a small amount of $\mathbf{3} \mathbf{a}$ was observed. The reaction of $\mathbf{1 a}$ with dimedone was also attempted with Ni powder (size $<150$ micron). The reaction was only $45 \%$ complete even after stirring for $24 \mathrm{~h}$. One of the most crucial result came from the reaction of $\mathbf{1 a}$ with dimedone in the presence of isolated $\mathrm{Ni}$ nanoparticles (obtained from the dispersion by the polyol method) which were washed repeated by with absolute ethanol followed by dispersal in ethylene glycol. The reaction was found to be complete in $15 \mathrm{~min}$ and $90 \%$ of $\mathbf{3 a}$ was isolated. All these results have been summarized in table 2 .

Reusability of nickel nanoparticles was examined by the reaction of $p$-bromobenzaldehyde (1a) with dimedone in the presence of PVP-Ni nanoparticles. Upon completion, the product (3a, 93\%) was extracted in ethyl acetate followed by isolation of ethylene glycol layer which was then used for subsequent cycles. The catalyst retained optimum activity up to four cycles after which a drop in yield (74\%) of the product (3a) was observed along with a increase in the particle size as is evident from the QELS data (figure 2).

The applicability of the catalyst was further extended to the reaction of 4-chlorobenzaldehyde with 4hyroxycoumarin under otherwise identical conditions. The reaction was complete in $15 \mathrm{~min}$ and $92 \%$ of $3,3^{\prime}-$ (4-chlorophenyl methylene)-bis (4-hydroxycoumarin) (4a) was obtained after work up. Subsequently, reactions of other aldehydes with 4-hydroxycoumarin also gave the corresponding biscoumarins in high yields (scheme 3, table 3).

Scheme 4 represents a plausible mechanism for the formation of tetraketones in the presence of PVPstabilized Ni nanoparticles. It is believed that $\mathrm{Ni}$ nanoparticles promote enolization in dimedone and facilitate domino Knoevenagel condensation Michael addition reaction leading to tetraketones. Also, it is a well known fact that polymer capped nanoparticles represent semi-heterogeneous catalytic system, as presence of polymer increases the interaction in the organic phase. So, in addition to promoting enolization, PVPstabilized Ni nanoparticles act as semi-heterogeneous high surface area catalyst and promote rapid tetraketone or biscoumarin formation.

Ethylene glycol, besides being a green solvent, proved advantageous for this transformation based on the solubility difference of the starting materials and the

Table 3. PVP stabilized Ni nanoparticles catalyzed synthesis of biscoumarins (4a-f) in ethylene glycol from aldehyde and 4-hydroxycoumarin.

\begin{tabular}{llccccc}
\hline & & & & & \multicolumn{2}{c}{ M.P. $\left({ }^{\circ} \mathrm{C}\right)$} \\
\cline { 5 - 7 } Entry & \multicolumn{1}{c}{$\mathrm{R}$} & Product & Time (min) & Yield (\%) & Obs. & Lit. \\
\hline 1. & $4-\mathrm{ClC}_{6} \mathrm{H}_{4}(\mathbf{1 a})$ & $\mathbf{4 a}$ & 15 & 92 & 250 & $252-254^{17}$ \\
2. & $4-\mathrm{O}_{2} \mathrm{NC}_{6} \mathrm{H}_{4}(\mathbf{1 b})$ & $\mathbf{4 b}$ & 15 & 93 & 230 & $232-234^{18}$ \\
3. & $4-\mathrm{HOC}_{6} \mathrm{H}_{4}(\mathbf{1 c})$ & $\mathbf{4 c}$ & 20 & 87 & 198 & $222-224^{18}$ \\
4. & $2-\mathrm{HOC}_{6} \mathrm{H}_{4}(\mathbf{1 d})$ & $\mathbf{4 d}$ & 15 & 94 & 244 & $247-248^{18}$ \\
5. & $3,4-\left(\mathrm{CH}_{3} \mathrm{O}\right)_{2} \mathrm{C}_{6} \mathrm{H}_{3}(\mathbf{1 e})$ & $\mathbf{4 e}$ & 20 & 90 & $270-272$ & $273-275^{17}$ \\
6. & Piperonyl $(\mathbf{1 f})$ & $\mathbf{4 f}$ & 15 & 89 & $244-246$ & $247-248^{18}$ \\
\hline
\end{tabular}




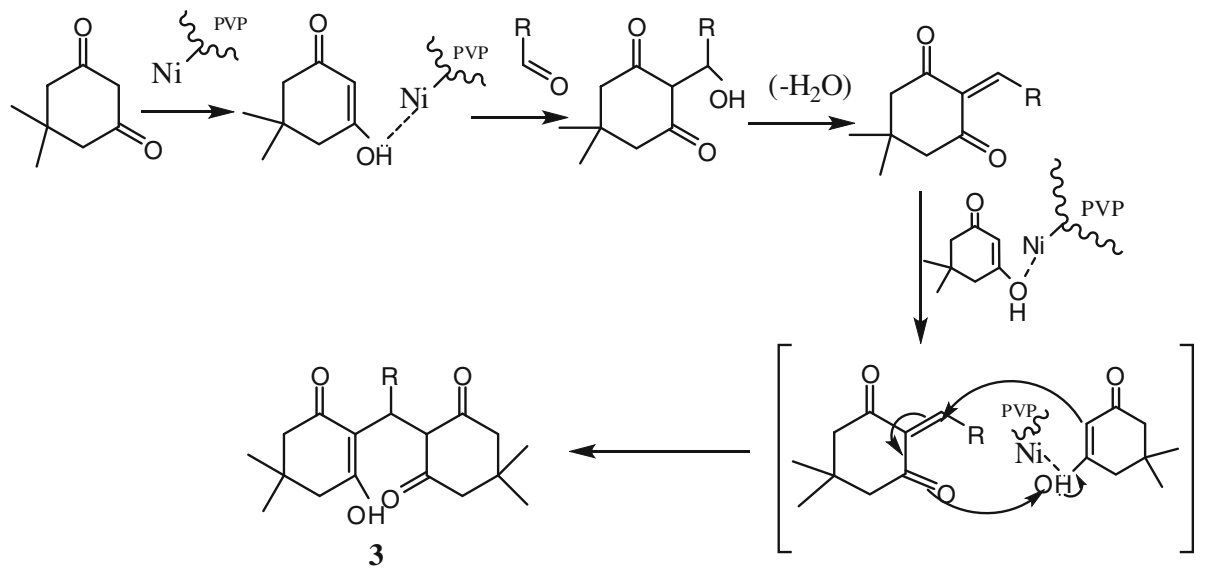

Scheme 4. Plausible mechanism for the formation of tetraketones in the presence of Ni nanoparticles.

final product. Hence, during the course of the reaction, the product precipitated out and was isolated simply by filtration and washing.

\section{Conclusion}

We have developed a practically efficient and novel protocol for the synthesis of tetraketones (3) and biscoumarins (4) using air stable PVP coated nickel nanoparticles as the catalyst in ethylene glycol at room temperature. The yields and the reaction time completely highlight the practical synthetic efficiency of this novel protocol.

\section{Acknowledgement}

$\mathrm{KV}$ is thankful to the Council of Scientific and Industrial Research (CSIR), New Delhi, India for the award of Junior and Senior Research Fellowships.

\section{References}

1. Ren Z, Cao W, Tong W and Jing X 2002 Synth. Commun. 321947

2. Mahavari G M, Ali S, Riaz N, Afza N, Malik A, Ashraf M, Iqbal L and Lateef M $2008 \mathrm{~J}$. Enzym. Inhib. Med. Ch. 2362

3. Poupelin J P, Saint-Rut G, Fussard-Blanpin O, Narcisse G, Vehida Ernouf G and Lakroix R 1978 Eur. J. Med. Chem. 13671367

4. Ion R M 1997 Progr. Catal. 255

5. Ion R M, Frackowiak D, Planner A and Wiktorowicz K 1998 Acta Biochim. Pol. 45833

6. Manolov I, Moessmer C M, Nicolova I and Danchev N 2006 Arch. Pharm. Chem. Life Sci. 339319

7. Lehmann J 1943 Lancet 241611

8. Khan K M, Iqbal S, Lodhi M A, Maharvi G M, Zia-Ullah, Choudhary M I, Rehman A and Perveen S 2004 Bioorg. Med. Chem. 121963
9. Horning E C and Horning M G 1946 J. Org. Chem. 11 95

10. Sadek E and Mohamed M 2004 J. Saudi Chem. Soc. 8 511

11. Darviche F et al 2007 Synth. Commun. 371059

12. Ramachary D B and Kishor M 2007 J. Org. Chem. 72 5056

13. King F E and Felton D G I 1948 J. Chem. Soc. 1371. doi:10.1039/JR9480001371

14. Kozlov N G 2006 Russian J. Org. Chem. 421668

15. Kantevari S, Bantu R and Nagarapu L 2007 J. Mol. Catal. A: Chem. 26953

16. Zhang P, Yu Y D and Zhang Z H 2008 Synth. Commun. 384474

17. Manolov I, Moessmer C M and Danchev N 2006 Eur. J. Med. Chem. 41882

18. Kidwai M, Bansal V, Mothsra P, Saxena S, Somvanshi R K, Dey S and Singh TP 2007 J. Mol. Catal. A: Chem. 26876

19. Alivisatos A P 1996 Science 271933

20. Majetich S A and Jin Y 1999 Science 284470

21. Yeung L K and Crooks R M 2001 Nano Lett. 114

22. Alonso F, Riente P and Yus M 2008 Tetrahedron 64 1847

23. Alonso F, Riente P and Yus M 2008 Tetrahedron Lett. 49 1939

24. Kidwai M, Mishra N K, Bansal V, Kumar A and Mozumdar S 2008 Catal. Commun. 9612

25. Alonso F, Riente P and Yus M 2008 Synlett 1289. doi:10.1055/s-2008-1072748

26. Alonso F, Riente P and Yus M 2008 Eur. J. Org. Chem. 294908

27. Saxena A, Kumar A and Mozumdar S 2007 J. Mol. Cat. A: Chem. 26935

28. Sapkal S B, Shelke K F, Shingate B B and Shingare M S 2009 Tetrahedron Lett. 501754

29. Khurana J M and Vij K 2010 Catal. Lett. 138104

30. Khurana J M, Sneha and Vij K 2011 Synth. Commun. doi:10.1080/00397911.2011.563404

31. Couto G G, Klein J J, Schreiner W H, Mosca D H, Oliveira A J A and Zarbin A J G 2007 J. Colloid. Interf. Sci. 311461

32. Khurana J M and Vij K 2011 Tetrahedron Lett. 52 3666 